\title{
Applications of high repetition rate tabletop soft $X$-ray lasers become a reality in several fields
}

\author{
J.J. Rocca ${ }^{1}$, M. Seminario ${ }^{1}$, M. Frati ${ }^{1}$, B.R. Benware ${ }^{1}$, H.L. Mancini ${ }^{2}$, J. Filevich ${ }^{1, a}$, \\ M.C. Marconi ${ }^{1, a}$, K. Kanizay ${ }^{1}$, A. Ozols ${ }^{1}$, I.A. Artioukov ${ }^{3}$, A.V. Vinogradov ${ }^{3}$, \\ Yu.A. Uspenskii ${ }^{3}$, F.G. Tomasel ${ }^{1}$ and V.N. Shlyaptsev ${ }^{4}$ \\ ${ }^{1}$ Department of Electrical and Computer Engineering, Colorado State University, Fort Collins, \\ CO 80523, U.S.A. \\ ${ }^{2}$ Universidad de Navarra, Spain \\ ${ }^{3}$ Lebedev Physical Institute, Moscow 117924, Russia \\ ${ }^{4}$ University of California at Davis, Livermore, U.S.A.
}

Abstract. For many years researchers have envisioned the development of compact high repetition rate tabletop soft $x$-ray lasers that could be routinely used in application in numerous disciplines. With demonstrated average powers of several mW and millijoule-level pulse energy at $46.9 \mathrm{~nm}$, the Ne-like Ar capillary discharge-pumped laser is the first compact laser to reach this goal. In this paper we summarize the development status of high repetition rate tabletop soft $x$-ray lasers based on capillary discharge excitation, and give examples of their successful use in several applications. Results of the use of a capillary discharge pumped $46.9 \mathrm{~nm}$ laser in dense plasma interferometry, soft x-ray reflectometry for the determination of optical constants, characterization of diffraction gratings, laser ablation of materials, and plasma generation are described. The observation of lasing at $52.9 \mathrm{~nm}$ line in Ne-like $\mathrm{Cl}$ with output pulse energy up to $10 \mu \mathrm{J}$ is also reported.

\section{Introduction}

Capillary discharge excitation of Ne-like Ar plasmas has generated $\mathrm{mW}$ average powers of coherent soft $x$-ray radiation and millijoule-level pulses in a tabletop set up [1,2]. Multi-Hertz repetition rate operation generated an average power of $\approx 3.5 \mathrm{~mW}$ at a wavelength of $46.9 \mathrm{~nm}$ [2]. The advanced degree of development of this laser is summarized in the next section. There is also significant interest in extending the availability of practical discharge-pumped short wavelength lasers to other wavelengths. In Seccion 3 we discuss the generation of laser pulses at $52.9 \mathrm{~nm}(23.4 \mathrm{eV})$ in the $3 \mathrm{p}-3 \mathrm{~s} \mathrm{~J}=0-1$ line of Nelike (1. Section 4 summarizes the results of several recent experiments that demonstrate for the first time the use of a tabletop soft $x$-ray laser in several diverse areas of science and technology. These areas include: plasma physics, materials characterization and processing, and the characterization of soft $x$-ray optics.

2. Development status of the $46.9 \mathrm{~nm}$ Ne-like Ar tabletop laser: demonstration of milliwatt average power and millijoule-level pulses

Table 1. Summary of $46.9 \mathrm{~nm}$ Capillary Discharge Table-Top Soft X-ray Laser parameters.

\begin{tabular}{|c|c|c|}
\hline LASER PARAMETER & & REF \\
\hline Pulse Energy & $0.88 \mathrm{~mJ}(a) 4 \mathrm{~Hz}$ & 2 \\
\hline Average Power & $3.5 \mathrm{~mW}$ & 2 \\
\hline Peak Power & $0.6 \mathrm{MW}$ & 2 \\
\hline Divergence & $\approx 4.6 \mathrm{mrad}$ & 2,3 \\
\hline Pulse Width & $1.2 \cdot 1.5 \mathrm{~ns}$ & 2,3 \\
\hline Peak Spectral brightness & $\begin{array}{c}2 \times 10^{25} \text { photons }\left(\mathrm{s} \mathrm{mm}^{2} \mathrm{mrad}^{2}\right. \\
0.01 \% \text { bandwidth })\end{array}$ & 4 \\
\hline
\end{tabular}

The Ne-like Ar capillary discharge laser is perhaps the most mature tabletop soft $\mathrm{x}$-ray laser developed to date. Table 1 summarizes the characteristics of this laser and its present output parameters. These laser output parameters were obtained utilizing aluminum oxide capillary channels $3.2 \mathrm{~mm}$ in diameter filled

\footnotetext{
Permanent address: FCEyN, LBA, Argentina.
} 
with preionized $\mathrm{Ar}$ gas at an optimized pressure of $\approx 460 \mathrm{mTorr}$. The plasma columns were excited by current pulses of $\approx 26 \mathrm{kA}$ peak amplitude with a $10 \%$ to $90 \%$ rise time of approximately 40 ns. Figure 1 illustrates the size of the capillary discharge Ne-like Ar laser. This capillary discharge-pumped laser occupies a table space of approximately $0.4 \mathrm{~m} \times 1 \mathrm{~m}$, a size comparable to that of many widely utilized visible or ultraviolet gas lasers.

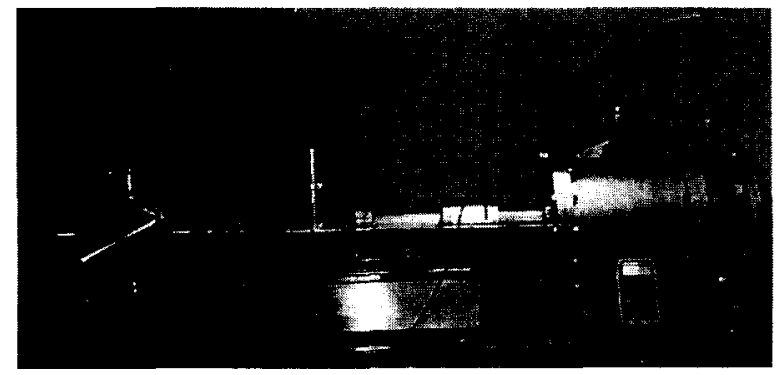

Figure 1. Photograph of capillary discharge soft $x$-ray laser (right) and applications chamber (left). A multimeter is shown in front of the laser to provide size reference.

In this laser the excitation current pulse is produced by discharging a water capacitor through a spark gap switch connected in scries with the capillary load. The laser average output pulse energy was measured to increase from $0.075 \mathrm{~mJ}$ for a plasma column $16 \mathrm{~cm}$ in length, to $0.88 \mathrm{~mJ}$ for the plasma column $34.5 \mathrm{~cm}$ in length. At the output of the longest capillary the laser beam intensity approaches $1 \mathrm{GW} / \mathrm{cm}^{2}$, and exceeds the saturation intensity by more than an order of magnitude.
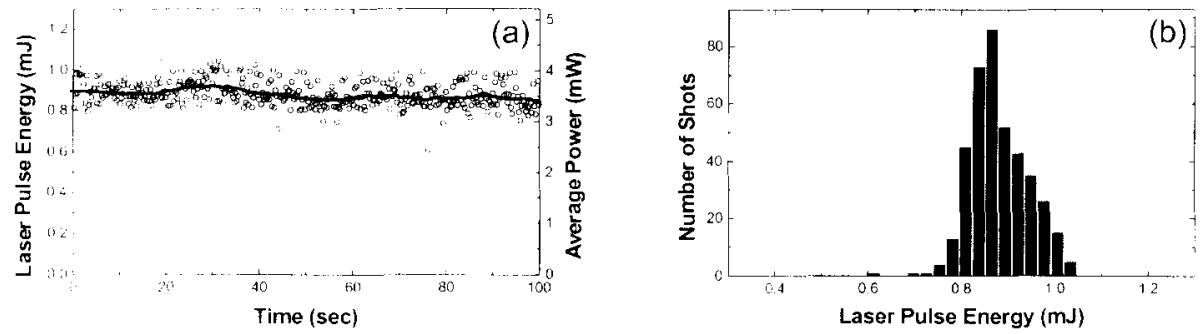

Figure 2. Measured output pulse energy and avcrage power of a table-top capillary discharge $46.9 \mathrm{~nm}$ laser operating at a repetition frequency of $4 \mathrm{~Hz}$. (a) Shot-to shot laser output energy and average output power computed as a walking average of 60 continuous laser pulses. (b) Distribution of the output pulse energy. Average pulse energy is $0.88 \mathrm{~mJ}$ and the standard deviation is $0.06 \mathrm{~mJ}$.

Figure 2 a shows the shot to shot variations of the measured laser output pulse energy and corresponding laser average power for a $34.5 \mathrm{~cm}$ long discharge operated at $4 \mathrm{~Hz}$ repetition rate. The average laser output power is about $3.5 \mathrm{~mW}$, corresponding to $>8 \times 10^{14}$ photons per second [2]. Figure $2 \mathrm{~b}$ shows the average laser output energy per pulse is $0.88 \mathrm{~mJ}$ and that the energy of the highest energy pulses exceeds $1 \mathrm{~mJ}$. More than 5000 laser shots were obtained from a single capillary. The full width at half maximum of the corresponding laser pulse is $1.5 \pm 0.05 \mathrm{~ns}$, longer than the $1.2 \mathrm{~ns}$ pulsewidth that we measured for an $18.2 \mathrm{~cm}$ long amplifier [3]. The average peak laser output power obtained with the longest plasma column is $\approx 0.6 \mathrm{MW}$. The output beam intensity distribution has an annular shape. The peak to peak divergence was measured to be about $4.6 \mathrm{mrad}$ for all capillary lengths between 18 and $34.5 \mathrm{~cm}$. Recent measurements of the spatial coherence indicate that full spatial coherence is approached with the longest capillaries and that the peak spectral brightness is about $2 \times 10^{25}$ photons/ $\left(\mathrm{s} \mathrm{mm}^{2} \mathrm{mrad}^{2} 0.01 \%\right.$ bandwidth) [4]. This value makes this table-top laser one of the brightest soft $x$-ray sources available.

\section{Demonstration at $52.9 \mathrm{~nm}$}

There is also significant interest short wavelength lasers to differ and photophysics can significan capable of causing single-photor the photoionization of He. The: technique that uses $\mathrm{He}$ as a carric We have demonstrated the gener Ne-like $\mathrm{Cl}$ utilizing a very co previously observed by $\mathrm{Y}$. Li et laser pulses produced by the pov In the $18.2 \mathrm{~cm}$ long discharge-p the amplified spontaneous cmis allowing for the generation of a up to $10 \mu \mathrm{J}$ were measured opera The gain media was generated $\mathrm{t}$ channel filled with pre-ionized c similar to that previously used $t$ was observed at $\mathrm{Cl}_{2}$ pressures $\mathrm{r}$ current pulses of approximately. this discharge, the fast current $[8,9]$ in which monopole collis inversion between the $3 \mathrm{p}^{\prime} \mathrm{S}_{0}$ and

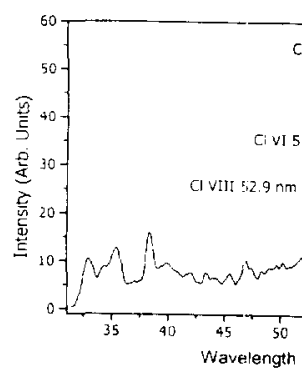

Figure 3. On-axis emission (a) Spectrum corresponding $t$ In the latter, the dominance

Figure 3 shows spectra of the ax the $\mathrm{J}=0-1$ laser line of $\mathrm{Ne}$-like $\mathrm{Cl}$ emission at the $52.9 \mathrm{~nm}$ waveler smaller than that of several neig contrast, at 224 mTorr, the optir magnitude more intense and con amplification in the $52.9 \mathrm{~nm}$ lin monitored with a vacuum photod 


\section{Demonstration at $52.9 \mathrm{~nm}$ capillary discharge laser in $\mathrm{Ne}-$ like $\mathrm{Cl}$}

There is also significant interest in extending the availability of practical saturated laser ablation tabletop short wavelength lasers to different regions of the spectrum. In particular, applications in photochemistry and photophysics can significantly benefit from repetitive laser sources of high energy photon that are capable of causing single-photon ionization of neutral species, yet fall short of the $24.6 \mathrm{eV}$ threshold for the photoionization of He. These applications include the study of nanoclusters created by optical, a technique that uses He as a carrier gas [5].

We have demonstrated the generation of laser pulses at $52.9 \mathrm{~nm}(23.4 \mathrm{eV})$ in the $3 \mathrm{p}^{1} \mathrm{~S}_{0}-3 \mathrm{~s}^{1} \mathrm{P}_{1}$ transition of Ne-like $\mathrm{Cl}$ utilizing a very compact capillary discharge [6]. Laser amplification of this line was previously observed by $\mathrm{Y}$. Li et al. in a plasma generated by exciting a solid $\mathrm{KCl}$ target with $450 \pm 20 \mathrm{~J}$ laser pulses produced by the powerful Asterix iodine laser facility at a rate of several shots per hour [7]. In the $18.2 \mathrm{~cm}$ long discharge-pumped plasma column used in the tabletop experiments reported hercin the amplified spontaneous emission intensity reached values of the order of the saturation intensity, allowing for the generation of a significantly greater laser output pulse energy. Laser pulses with energy up to $10 \mu \mathrm{J}$ were measured operating the discharge at repetition rates between 0.5 and $1 \mathrm{~Hz}$.

The gain media was generated by rapidly exciting a $3.2 \mathrm{~mm}$ inside diameter aluminum oxide capillary channel filled with pre-ionized chlorine gas with a fast current pulse. The capillary discharge set up was similar to that previously used to obtain lasing in $\mathrm{Ne}$-like $\mathrm{Ar}$ at high repetition rates [3]. Amplification was observed at $\mathrm{Cl}_{2}$ pressures ranging from 180 to 300 mTorr. The plasma columns were excited by current pulses of approximately $23 \mathrm{kA}$ peak amplitude and $10-90 \%$ rise-time of approximately $25 \mathrm{~ns}$. In this discharge, the fast current pulse rapidly compresses the plasma creating a small diameter column [8.9] in which monopole collisional electron excitation of $\mathrm{Ne}$-like $\mathrm{Cl}$ ions creates a large population inversion between the $3 \mathrm{p}^{1} \mathrm{~S}_{0}$ and $3 \mathrm{~s}^{1} \mathrm{P}_{1}$ levels, resulting in strong amplification at $52.9 \mathrm{~nm}$.
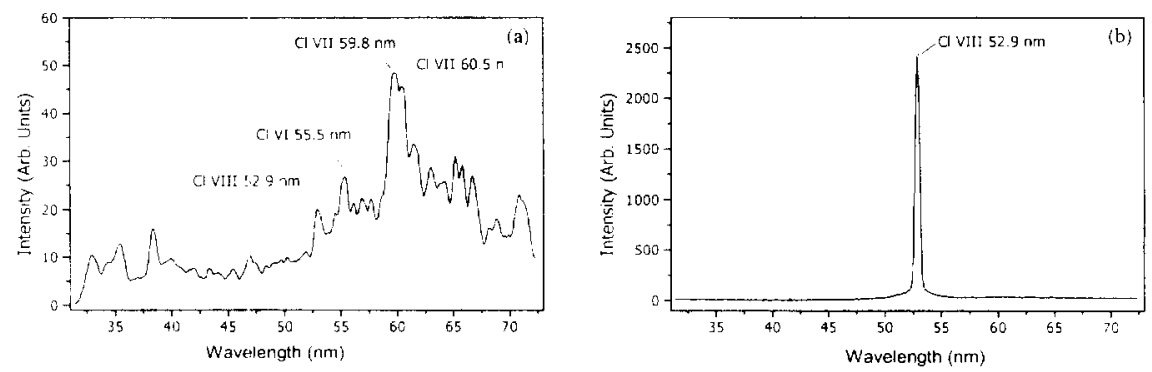

Figure 3. On-axis emission spectra of the $\mathrm{Cl}$ capillary discharge plasma in the region between 30 and $70 \mathrm{~nm}$. (a) Spectrum corresponding to a $120 \mathrm{mT}$ Torr discharge. (b) Spectrum corresponding to a 224 m'Torr discharge In the latter, the dominance of the $59.2 \mathrm{~nm} \mathrm{Ne}$-like $\mathrm{Cl}$ transition is a clear indication of strong amplification.

Figure 3 shows spectra of the axial emission of the discharge, covering a $40 \mathrm{~nm}$ region in the vicinity of the $J=0-1$ laser line of Ne-like Cl. The spectrum obtained at a pressure of 120 mTorr (Fig. 3a), shows line emission at the $52.9 \mathrm{~nm}$ wavelength of the laser transition. However the intensity of this line is weak, smaller than that of several neighboring transitions of $\mathrm{Cl}$ VI and $\mathrm{Cl}$ VII, which cannot be inverted. In contrast, at $224 \mathrm{mT}$ Torr, the optimum pressure for lasing (Fig, 3b), the laser line is over two orders of magnitude more intense and completely dominates the entire spectrum. This is clear evidence of large amplification in the $52.9 \mathrm{~nm}$ line. The energy and temporal evolution of the laser output pulse were monitored with a vacuum photodiode. 


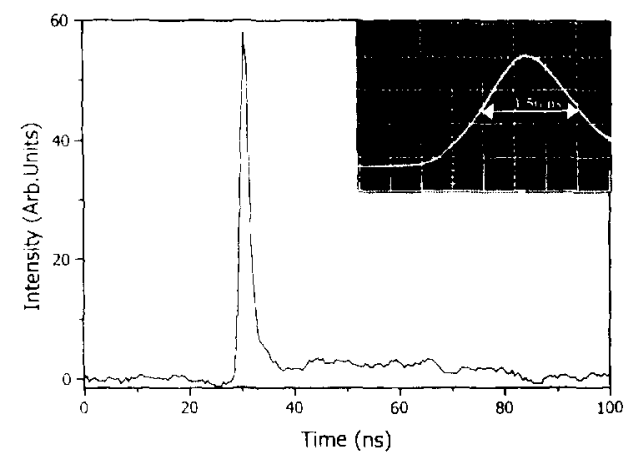

Figure 4. Temporal evolution of the $52.9 \mathrm{~nm} \mathrm{Ne-like} \mathrm{Cl} \mathrm{laser} \mathrm{output} \mathrm{pulse.} \mathrm{The} \mathrm{insert} \mathrm{in}$ the top right comer corresponds to the signal recorded with a fast vacuum photodiode and a $1-\mathrm{GHz}$ bandwidth analog oscilloscope. The signal corrected for the limited bandwidth of the detection system yields a laser FWHM pulsewidth of $1.46 \mathrm{~ns}$.

Figure 4 shows a laser pulse with energy of $10 \mu \mathrm{J}$ measured operating the system at a repetition frequency of $0.5 \mathrm{~Hz}$. However, the shot to shot variation in the laser pulse energy was significantly larger than those measured operating the laser at $46.9 \mathrm{~nm}$ using $\operatorname{Ar}$ [2.3]. The measurement of multiple shots yielded an averaged laser FWHM pulse of $1.46 \pm 0.25 \mathrm{~ns}$. The beam was observed to present maximum intensily on axis and a FWHM divergence of $\sim 4 \operatorname{mrad}[6]$.

\section{Applications}

\subsection{Soft $x$-ray laser interferometry of dense plasmas}

The development of gain-saturated soft x-ray lasers has opened the possibility to extend laser interferometry to large-scale plasmas of very high density that can not be probed with optical lasers [10]. Our group has previously demonstrated plasma interferometry combining a $46.9 \mathrm{~nm}$ capillary discharge tabletop laser with a wavefront-division interferometer based on Lloyd's mirror [11-12]. More recently. we have developed a novel soft $\mathrm{x}$-ray amplitude-division interferometer in which diffraction gratings are used as beam splitters in a Mach-Zehnder configuration. By properly tailoring the gratings this instrument can be made to operate at any selected soft $x$-ray wavelength. The interferometer was used in combination with the $46.9 \mathrm{~nm}$ capillary discharge tabletop laser to map the electron density evolution of a $2.7 \mathrm{~mm}$ long line-focused laser-created plasma generated on a $\mathrm{Cu}$ slab target focusing $\mathrm{Nd}$ :YAG laser pulses of $\sim 0.36 \mathrm{~J}$. We have been able to probe the plasma at locations as close as $25-30 \mu \mathrm{m}$ from the target where the electron density is approximately $5 \times 10^{16} \mathrm{~cm}^{-3}$, and the density gradient is steep. Another series of measurements for a $1.8 \mathrm{~mm}$ long line-focus plasma created by $0.6 \mathrm{~J} \mathrm{Nd:YAG}$ laser pulses probed electron densities up to $1 \times 10^{20} \mathrm{~cm}^{-3}$. Ray tracing computations show that these measurements would be difficult to realize with an UV laser probe due to strong refraction. These results are discussed in more detail in the paper by Filevich et al. [13].

\subsection{XUV Reflectometry}

We took advantage of the high repetition rate of the capillary discharge laser to conduct reflectivity measurements as a function of angle. These measurements resulted in the determination of optical constants at $\lambda=46.9 \mathrm{~nm}$ for several materials, and in the characterization of XUV multilayer mirrors. The experimental setup used to perform soft $x$-ray reflectometry is shown in figure 5 . The measurements were conducted in a vacuum chamber placed at about $1.5 \mathrm{~m}$ from the exit of the $\mathrm{Ne}$-like $\mathrm{Ar}$ capillary discharge laser. The samples were mounted on the axis of a rotational stage driven by a stepper motor, which allowed for the selection of angles of incidence between 0 and 90 degrees. The intensity of the reflected beam was recorded with a vacuum photodiode (labeled " $A$ " in fig. 5), that was mounted on a lever am that followed the angular motion of the reflected beam. To overcome scattering of the data due to shot to shot intensity variation of the laser, the intensity of the reflected beam was normalized by the intensity of the incident beam measured by scanning the angle $1 \mathrm{~Hz}$.

Figure 5. Schematic diagram of $\mathrm{tl}$

\subsubsection{Determination of optica}

The optical constants for Si, GaF obtained by fitting the measured is an example of the reflectance of InP with a 100 orientation, co sample. The results, obtained fro intensity of the laser source is normal incidence where the refle models that take into account the materials in a natural atmospheric on the measurement, the samples approximately $5 \mathrm{~min}$ and were th untreated samples that had differ bulk material. This suggests that the optical constants for the $b$ measurements of the optical cons

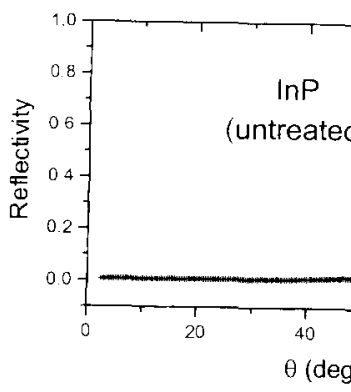

Figure 6. Measured and calculatt Before chemical treatment. The $d$ solid curve considering a surface 1 After chemical treatment. The do solid curve considering a surface 1 . wavelength, while for the rest of $t$ 
intensity of the incident beam for each laser pulse. The angular dependence of the reflectivity was measured by scanning the angle of incidence while repetitively firing the laser at a repetition frequency of
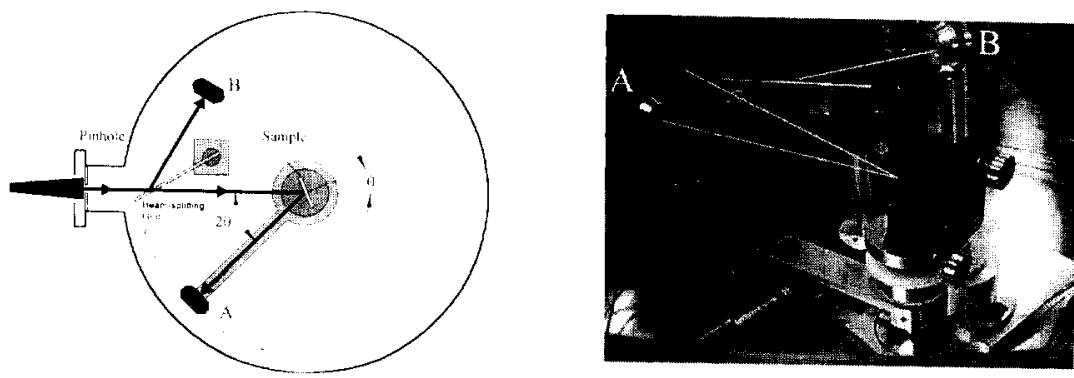

Figure 5. Schematic diagram of the laser reflectometer used in the measurement of XUV optical constants of matcrials

cy of

those

d an

axis

laser

$[10]$

harge

ently.

gs are

iment

lation

lone

$0.36 . \mathrm{I}$.

re the

ies of

ectron

fficult tail in

ctivily optical is. The zments ipillary motor. of the d on a ata due by the

\subsubsection{Determination of optical constants of materials}

The optical constants for Si, GaP, InP, GaAs, GaAsP and Ir at a wavelength of $46.9 \mathrm{~nm}(26.5 \mathrm{eV})$ were ubtained by fitting the measured angular dependence of the reflectivity with the Fresnel formula. Figure 6 is an example of the reflectance data obtained as a function of incident angle for a bulk crystalline sample of InP with a 100 orientation, consisting of 300 contiguous laser pulses for a 90 degree rotation of the sample. The results, obtained from the fits of the experimental data, are summarized in table 2 . The high mensity of the laser source is an advantage for the accurate measurement of the reflectivity at near Jormal incidence where the reflectivity of most materials is low. Our analysis of the data made use of models that take into account the presence of a surface layer of contamination, which develops on most materials in a natural atmospheric environment. In order to characterize the influence of the surface layer in the measurement, the samples were chemically treated in a 5\% solution of HF in distilled water for ipproximately $5 \mathrm{~min}$ and were then rinsed with acetone and methanol. Measurement of the treated and untreated samples that had different surface layer characteristics gave similar optical constants for the yulk material. This suggests that the approach used in this work is capable of yielding reliable values of the optical constants for the bulk material in the presence of surface layer contaminants. The ncasurements of the optical constants of InP and GaAsP constitute the first experimental values at this
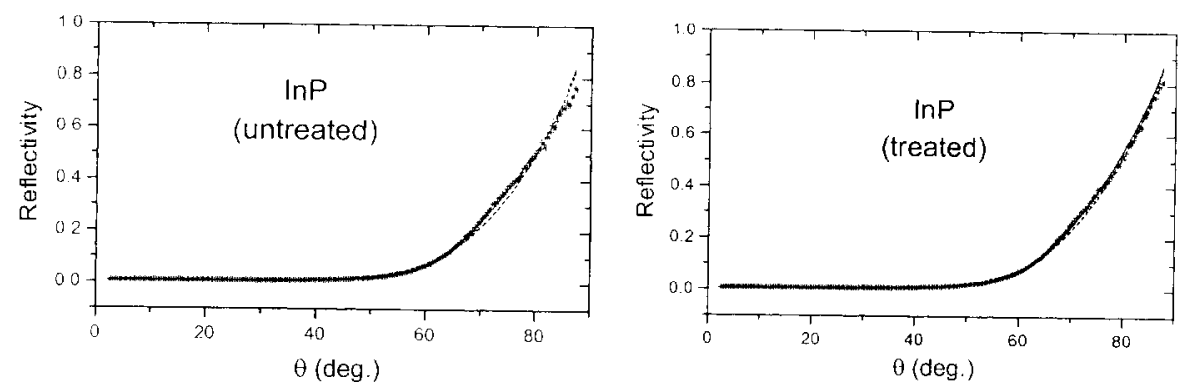

Figure 6. Measured and calculated reflectivity for 100 crystalline $\operatorname{In}^{\mathrm{P}}$ as a function of incident angle $\theta$. (a) Before chemical treatment. The dotted curve corresponds to: $\tilde{n}_{\mathrm{b}}=0.92 \cdot i \cdot 0.14$ without the surface layer, the solid curve considering a surface layer: $\tilde{n}_{b}=0.88+i \cdot 0.087$ (layer: $\tilde{n}_{1}=0.82+\mathrm{i} \cdot 0.39$, thickness $d_{1}=1.8 \mathrm{~nm}$ ). (b) After chemical treatment. The dotted curve corresponds to: $\tilde{n}_{\mathrm{b}}=0.91+i \cdot 0.13$ without the surface layer, the solid curve considering a surface layer: $\tilde{n}_{b}=0.88+i 0.09$ (layer: $\tilde{n}_{l}=0.84+i \cdot 0.26$, thickness $d_{1}=2.5 \mathrm{~nm}$ ).

ravelength, while for the rest of the materials the values obtained for the other samples are in most cases 
in good agreement with tabulated values. These measurements and the analysis of the data are discussed in more detail in the paper by I. Artioukov in $[14,15]$

Table 2. Measured optical constants of materials at $46.9 \mathrm{~nm}$.

\begin{tabular}{|c|c|c|c|c|c|c|}
\hline \multirow[t]{2}{*}{ No } & \multirow[t]{2}{*}{ Sample } & \multirow[t]{2}{*}{ Treated } & \multicolumn{2}{|c|}{ This work } & \multicolumn{2}{|c|}{ Ref.[16] } \\
\hline & & & $\mathrm{n}$ & $\mathrm{k}$ & $\mathrm{n}$ & $k$ \\
\hline 1 & \multirow[t]{2}{*}{ Si } & No & 0.82 & 0.015 & \multirow[t]{2}{*}{0.803} & \multirow[t]{2}{*}{0.0178} \\
\hline 2 & & Yes & 0.80 & 0.021 & & \\
\hline 3 & \multirow[t]{2}{*}{ GaP } & No & 0.82 & 0.052 & \multirow[t]{2}{*}{$\mathrm{N} / \mathrm{A}$} & \multirow[t]{2}{*}{0.100} \\
\hline 4 & & Yes & 0.82 & 0.055 & & \\
\hline 5 & \multirow[t]{2}{*}{ InP } & No & 0.88 & 0.087 & \multirow[t]{2}{*}{$N / A$} & \multirow[t]{2}{*}{$N / A$} \\
\hline 6 & & Yes & 0.89 & 0.090 & & \\
\hline 7 & GaAs & No & 0.84 & 0.060 & $N / A$ & 0.083 \\
\hline 8 & GaAsP & No & 0.83 & 0.059 & & \\
\hline 9 & $\mathrm{Ir}$ & No & 0.81 & 0.53 & 0.67 & 0.69 \\
\hline
\end{tabular}

\subsubsection{Angular dependent reflectivity of $\mathrm{Si} / \mathrm{Sc}$ multilayer mirror}

Utilizing the reflectometer described above, measurements were made of the angular dependent reflectivity of $\mathrm{Si} / \mathrm{Sc}$ multi-layer mirrors designed for use at $46.9 \mathrm{~nm}$. The multilayer coatings were deposited on super-polished borosilicate substrates by dc magnetron sputtering with a period of $18-27 \mathrm{~nm}$

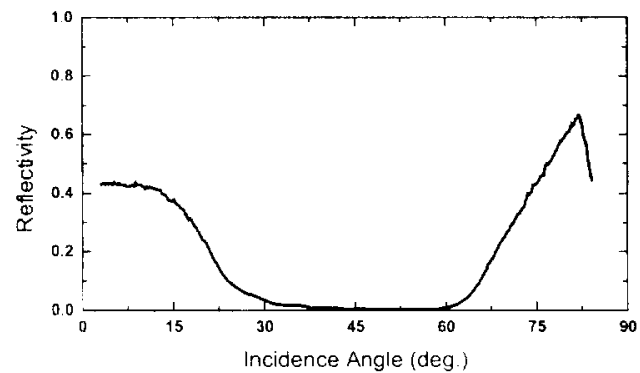

Figure 7. Measured reflectivity of a Si Sc multilayer mirror at $46.9 \mathrm{~nm}$ as a function of incidence angle.

and a ratio of layer thickness $\mathrm{H}(\mathrm{Sc}) / \mathrm{H}(\mathrm{Si})=0.786$ [17]. As an example, figure 7 shows the measured reflectivity as a function of incidence angle for a mirror designed to operate at normal incidence. The graph corresponds to the average of four runs. The runs varied in the number of data points collected from 200 to 400 for a scan angle of 90 degrees. A near normal incidence reflectivity of $43 \%$ was measured at 1.6 degrees.

\subsection{Generation of a polarized soft $x$-ray beam and application to the characterization of diffraction gratings}

We have also demonstrated the generation of a highly polarized soft $x$-ray beam. The radiation emitted by a high average power discharge pumped tabletop Ne-like Ar soft x-ray laser operating at $46.9 \mathrm{~nm}$ was polarized using a pair of $\mathrm{Si} / \mathrm{Sc}$ multilayer mirrors designed for 45 degree operation. A degree of polarization greater than 0.96 was obtained. These results are discussed in more detail in these proceedings in the paper by Vinogradov et al. [18], and in a recent paper by Benware et al [19]. Polarized and unpolarized laser beams $\mathrm{p}$ diffraction grating. The efficic of incidence and compared wi valuable benchmarks to imp gratings, and illustrate the $p$ characterization of short wave sufficient space to give a com near future.

\subsection{Soft $x$-ray laser ablation}

Focused soft $x$-ray laser bean opening new applications for focus làser pulses from a colli [20]. Here we summarize the $c$ capillary discharge soft $x$-ray laser. The experimental setup focal region is shown in figure

Figure 8. E

The soft $x$-ray laser pulses $h$ generated at a repetition rate $o$ beam was focused by a spheri reflectivity located in a vacuur was positioned at normal incic was focused on axis, where it il strip. The focused laser beam $v$ and brass when the samples are of the imprints on the metal su point and heat conductivity of can give useful two-dimension: evolution of the laser intensit translation stage driven by a c stage was positioned at an an positions along the optical ax repetitively firing the laser at a Figure 9 is a scanning electron progression of ablation patterns 
Ire discussed

$r$ dependent Jatings were of 18-27 $\mathrm{mm}$

he measured idence. The nts collected of $43^{\circ} \%$ was

\section{f diffraction}

in emitted by $46.9 \mathrm{~nm}$ was A degree of tail in these 91. Polarized and unpolarized laser beams produced by this tabletop laser were used to characterize the efficiency of a diffraction grating. The efficiencies for different diffraction orders were measured as a function of angle of incidence and compared with the results of model simulations. This measurement technique provides valuable benchmarks to improve electromagnetic codes used in the design of soft x-ray diffraction gratings, and illustrate the potential of compact tabletop soft $x$-ray lasers as a new tool for the characterization of short wavelength optics at the manufacturer's site. In this proceedings we do not have sufficient space to give a complete report on these results, and they will be published elsewhere in the ncar future.

\subsection{Soft $x$-ray laser ablation}

Focused soft $x$-ray laser beams have the potential to reach very high intensities and energy densities, opening new applications for short wavelength coherent radiation. Preliminary results of an attempt to focus laser pulses from a collisional soft $\mathrm{x}$-ray laser pumped by a large optical laser have been reported [20]. Here we summarize the characterization of a focused $46.9 \mathrm{~nm}$ laser beam generated by a Ne-like Ar capillary discharge soft $x$-ray laser, and the results of the first laser ablation experiment with a soft $x$-ray laser. The experimental setup used to focus the laser beam and characterize its intensity distribution in the focal region is shown in figure 8 .

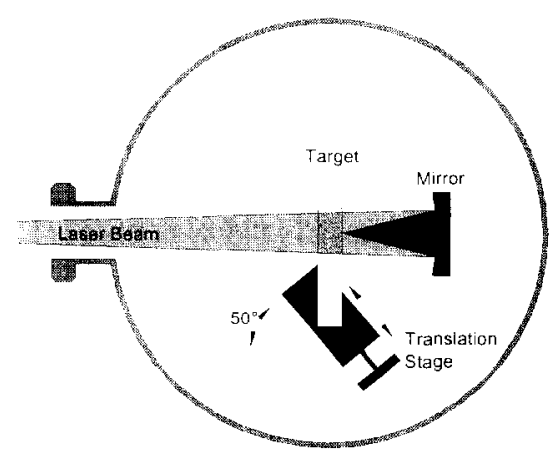

Figure 8. Lxperimental setup used to focus the soft $\mathrm{x}$-ray laser beam.

The soft $x$-ray laser pulses had an energy of about $0.13 \mathrm{~mJ}$ and $1.2 \mathrm{~ns}$ FWHM duration and were generated at a repetition rate of $1 \mathrm{~Hz}$ by amplification in a $18.2 \mathrm{~cm}$ long Ar capillary plasma The laser beam was focused by a spherical $(\mathrm{R}=10 \mathrm{~cm}) \mathrm{Si} / \mathrm{Sc}$ multilayer-coated mirror of $\approx 40 \%$ normal incidence reflectivity located in a vacuum chamber at $256 \mathrm{~cm}$ from the exit of the capillary amplifier. The mirror was positioned at normal incidence with the purpose of minimizing aberrations and the reflected beam was focused on axis, where it impinged on the flat face of a target consisting of a thin ( $2 \mathrm{~mm}$ thick) metal strip. The focused laser beam was observed to have sufficient intensity to ablate aluminum, stainless stee] and brass when the samples are positioned within several hundred $\mu \mathrm{m}$ from the focus. The characteristics of the imprints on the metal surface depend not only on the intensity distribution, but also on the melting point and heat conductivity of the sample, and on the duration of the laser pulse [21]. Nevertheless, they can give useful two-dimensional information of the focused laser beam intensity distribution. To map the evolution of the laser intensity distribution along the propagation axis we mounted the target on a translation stage driven by a computer controlled stepper motor. The axis of motion of the translation stage was positioned at an angle with respect to the optical axis. Series of imprints of the beam for positions along the optical axis were obtained by continuously moving the translation stage while repetitively firing the laser at a repetition rate of $1 \mathrm{~Hz}$.

Figure 9 is a scanning electron microscope (SEM) photograph of the surface of a brass target showing the progression of ablation patterns obtained as the target was moved away from the mirror and towards the 
focus. Each ablation pattern is the result of a single laser shot. At an axial distance of a few hundred $\mu \mathrm{m}$ from the focal region the ablation patterns have the shape of thin annular disks. These rings show good azimuthal symmetry, except for a small discontinuity where the incoming beam was blocked by the target. As the focal region is approached the thickness of the ablated rings increases, and a central spot
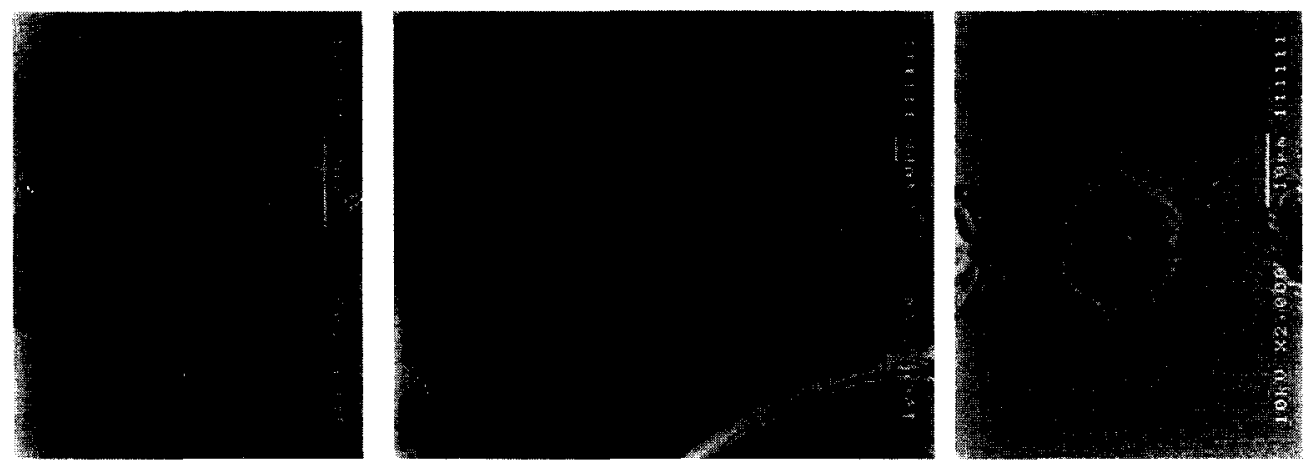

Figure 9. Scanning electron microscope images of the ablation patterns obtained moving a brass sample towards the focus. Each ablation pattem corresponds to a single laser shot. The composition of the brass used in this experiment was by weight $60.95 \% \mathrm{Cu}, 39.05 \% \mathrm{Zn}$ with small $\mathrm{Al}$ impurities.

develops. The depth of the rings was measured to be $\approx 2 \mu \mathrm{m}$. Finally, very near the focus the patterns evolve into a single spot with a deep hole on axis. The smallest spot has an outer diameter of about $17 \mu \mathrm{m}$ and contains a deep central hole of about 2-3 $\mu \mathrm{m}$ diameter.

To increase the understanding of the characteristics of the laser beam in the focal region and to obtain an estimate of the power density deposited we analyzed these results with ray-tracing computations. Figure 10 shows the computed radial cross section of the beam intensity distributions in the focal region. For comparison with the experiment the measured boundaries of the ablated regions are represented as black dots in the same figure. All the major features of the observed ablation profiles of figure 9 are well described by the ray tracing computations.

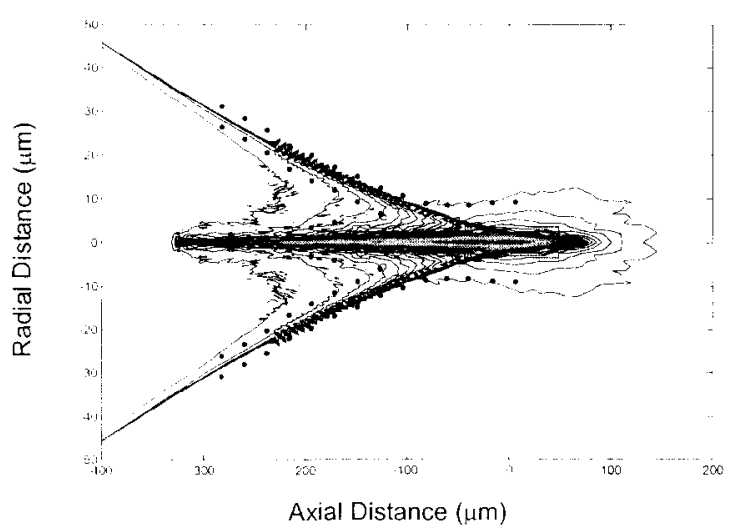

Figure 10. Computed radial cross section of the beam in the focal region. The dots correspond to the measured boundaries of the ablated patterns.

The computations show that at a few hundred $\mu \mathrm{m}$ from the focal region the highest concentration of rays defines a thin ring. Also in accordance with the experiment a central peak is observed to develop as the focal region is approached. Both features are the result of the spherical aberration that causes the rays to converge and cross at those locations. Similarly, the spherical aberration causes the central peak, which begins to develop when the outermost rays converge on the axis. Near the so-called "plane of minimum confusion" the intensity distribu responsible for the deep central diameter region is estimated to intersect this region. The analysi dominantly limited by the spheri

\subsection{Plasma generation with a f}

The successful demonstration of the previous section opens th characteristics. The fact that the is capable of inducing single ph mechanisms of these plasmas fro plasmas generated with the focus

Figure 11. Experimental set-up us

Focusing of the beam of the 46. multilayer coated mirror $(\mathrm{R}=10$ radiation onto a $\mathrm{MCP} / \mathrm{CCD}$ detec multilayer coated mirror $(\mathrm{R}=20 \mathrm{c}$ were used in the experiment. $F$ excitation of carbon, aluminum, is observed. The results clearly d Future work will include emissio

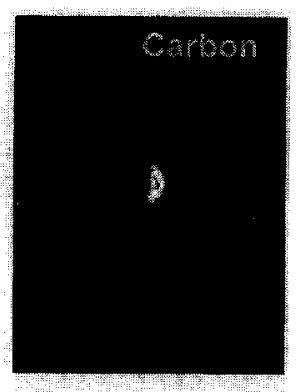

Figure 12. Images of the soft $x$-ray 
Ired $\mu \mathrm{m}$ w good by the ral spot

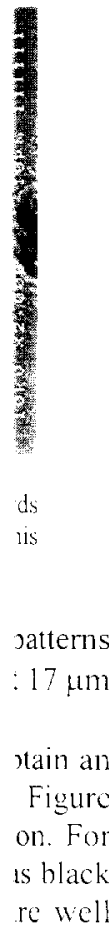

tain an Figure is black re well

I of rays $p$ as the 2 rays 10 \&, which sinimum confusion" the intensity distribution is computed to be dominated by the sharp central peak, which is responsible for the deep central hole observed in the SEM images. The average intensity within a $2 \mu \mathrm{m}$ diameter region is estimated to be greater than $1 \times 10^{11} \mathrm{~W} / \mathrm{cm}^{2}$ from the computed fraction of rays that intersect this region. The analysis also confirms that the minimum spot size obtained in this experiment is dominan:ly limited by the spherical aberration [19].

\subsection{Plasma generation with a focused soft $x$-ray laser beam}

The successful demonstration of focusing of a soft $\mathrm{x}$-ray laser beam to the large intensities mentioned in the previous section opens the possibility of generating and studying dense plasmas of unique characteristics. The fact that the critical density for $46.9 \mathrm{~nm}$ laser radiation is $510^{23} \mathrm{~cm}^{-3}$ and that the laser is capable of inducing single photon ionization of the target atoms differentiates the energy deposition mechanisms of these plasmas from those of conventional laser-created plasmas. The set-up used to image plasmas generated with the focused soft $x$-ray laser beam is illustrated in figure 11 .

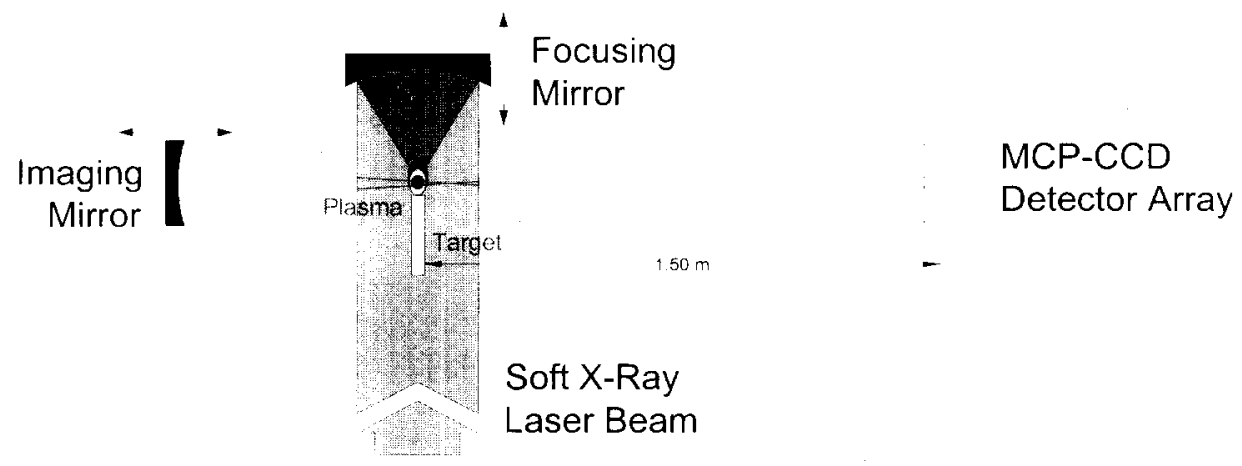

Figure 11 . Lxperimental set-up used to generate a plasma with a focused soft $x$-ray laser beam and image it

Focusing of the beam of the $46.9 \mathrm{~nm}$ capillary discharge laser was again accomplished with an spherical multilayer coated mirror $(\mathrm{R}=10 \mathrm{~cm}$, reflectivity $\sim 42$ percent). Imaging of the plasma VUV/soft $\mathrm{x}$-ray radiation onto a MCP/CCD detector with $\sim 14 \mathrm{x}$ magnification was accomplished using a second spherical multilayer coated mirror $(\mathrm{R}=20 \mathrm{~cm})$. Soft $\mathrm{x}$-ray laser pulses of approximately $0.35 \mathrm{~mJ}$ and $1.5 \mathrm{~ns}$ duration were used in the experiment. Figure 12 shows the images of plasmas generated by soft $x$-ray laser excitation of carbon, aluminum, tin, and copper targets. A Soft $x$-ray emitting plasma region of $\sim 100 \mu \mathrm{m}$ is observed. The results clearly demonstrate the creation of plasmas with a focused soft $x$-ray laser beam Future work will include emission spectroscopy to study the plasma characteristics.
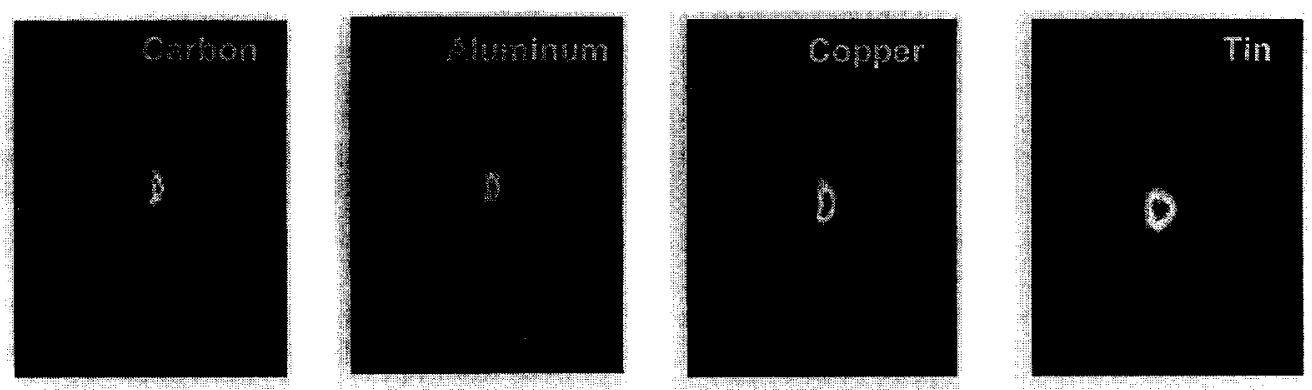

Figure 12. Images of the soft $\mathrm{x}$-ray/VUV emission from soft $\mathrm{x}$-ray laser-created plasmas in $\mathrm{C}, \mathrm{Al}, \mathrm{Cu}$ and $\mathrm{Sn}$. 


\section{Conclusions}

In summary, capillary discharge-pumped lasers are the first tabletop soft x-ray lasers to reach a level of development that allows their routine use in numerous applications. The average coherent power per unit of spectral bandwidth of the Ne-like Ar laser is similar to that of a third generation synchrotron beam line, and its high peak spectral brightness makes it one of the brightest sources of soft $\mathrm{x}$-ray radiation. The proof of principle experiments described above show that tabletop capillary discharge lasers are a powerful source of coherent short-wavelength radiation that can impact numerous fields.

\section{Acknowledgements}

The development of the soft $x$-ray laser was supported by the National Science Foundation. The plasma interferometry work was supported by the U.S. Department of Energy grant DE-FG03-98DP00208. We gratefully acknowledge a grant from the W.M.Keck Foundation. We also acknowledge the support of tho Colorado CPOP program, and the U.S. Civilian Research and Development Foundation (CRDF) for the collaboration that resulted in the development of the multi-layer mirrors. M. Marconi acknowledges the support of CONICET. We are thankful M. Forsythe and O.E. Martinez for their important contributions

\section{REFERENCES}

1. J. J. Rocca, Rev. Sci. Instru. 70, 3799 (1999).

2. C. D. Macchietto, B. R. Benware and J. J. Rocca, Opt. Lett., 24, 1115 (1999)

3. B.R. Benware, C.D. Macchietto, C.H. Moreno, and J.J. Rocca, Phys. Rev. Lett., 81, 5804, (1998)

4. Y. Liu, M. Seminario, F.G. Tomasel, C. Chang, J.J. Rocca, and D.T. Attwood, "High Average Power Soft X-ray Laser Beams Approaching Full Spatial Coherence". Submitted, (2000).

5. M. Foltin, G. J. Stueber, and E. R. Bernstein, J. Chem. Phys. 111, 21, 9577 (1999)

6. M. Frati, M. Seminario and J.J. Rocca. Opt. Lett. 25, 1022 (2000)

7. Y. Li, G. Pretzler and E. E. Fill, Phys. Rev. A, 52, R3433 (1995).

8. J.J. Rocca, V.N. Shlyaptsev, F.G. Tomasel, O.D. Cortazar, D. Hartshom, and J.L.A. Chilla.. Phys. Rev. Lett., 73, 2192 (1994).

9. J.J. Rocca, D.P. Clark, J.L.A. Chilla and V.N. Shlyaptsev. Phys. Rev. Lett., 77, 1476 (1996).

10. L.B. Da Silva et al. Phys. Rev. Lett. 74, 3991 (1995).

11. J.J. Rocca, C.H. Moreno, M.C. Marconi and K. Kanizay. Opt. Lett., 24, 420, (1999).

12. C.H. Moreno, M.C. Marconi, K. Kanizay, J.J. Rocca, Yu. A. Unspenskii, A.V. Vinogradov and Yu.A. Pershin. Phys. Rev. E, 60, 911 (1999).

13. J. Filevich et al., in these proceedings and J. Filevich, K. Kanizay, M. C. Marconi, J. L. A. Chilla, and J. J. Rocca, Opt. Lett. 25, 5, 356 (2000)

14. I.A. Artioukov et al., in these proceedings

15. I.A. Artioukov, B.R. Benware, J.J. Rocca, M. Forsythe, Yu. A. Uspenskiia and A.V. Vinogradov IEEE J. Sel. Topics in Quant. Elect. 5, 1495, (1999).

16. E.D. Palik, "Handbook of Optical constants of Solids". San Diego, CA: Academic, (1998).

17. Yu.A. Uspenskii, V.E. Levashov, A.V. Vinogradov, A.I. Fedorenko, V.V. Kondratenko, Yu.P. Pershin, E.N. Zubarev, and V.Yu. Fedotov, Opt.Lett., 23, 771, (1998).

18. A.Vinogradov et al., in these proceedings.

19. B. R. Benware, A.Ozols, J. J. Rocca, I.A. Artioukov, V.V. Kodratenko and A.V. Vinogradov. Opt. Lett., 24, 1724, (1999)

20. Ph. Zeitoun, S. Sebban, K. Murai, H. Tang, et.al., in X-ray Lasers 1998, eds. Y. Kato, H. Takuma and H. Daido, , IoP Conf. Proc. No. 159 (IOP, Bristol), pp. 6770, (1998)

21. J.C. Miller and R.F. Haglund. "Laser ablation and desorption". (Academic, San Diego, CA, (1998)

\section{New regime of Thom with X-ray lasers}

\author{
H.A. Baldis ${ }^{1,2}$, J. Dunn ${ }^{3}, N$ \\ and R. Shepherd ${ }^{3}$ \\ ${ }^{1}$ Institute for Laser Science a \\ P.O. Box 808, Livermore, CA \\ ${ }^{2}$ Department of Applied Scier \\ ${ }^{3}$ Lawrence Livermore Natione \\ ${ }^{4}$ Theoretical Physics Institute \\ T6G 2J1, Canada
}

\begin{abstract}
In this paper we $d$ laser for probing hot, high-d laser as a probe. Theoretical produced plasmas. The thres with plasma thermal emissio temperature is given.
\end{abstract}

\section{INTRODUCTION}

There has been much progress producing megawatts of stimulate schemes [1-4]. This opens the microscopy [5], x-radiography [6 ray laser pump sources. Longer applications such as interferometr densities, typically in the range 1 possibility of probing orders of $m$ Thomson scattering from plasma parameters, distribution $f$ become a standard technique for we demonstrate through calculati for probing high-density plasmas of the spectrometer and sensitivit temperature in short pulse laser-p [11] and proposed [12] for the dia We first discuss the gener discussion is to demonstrate the $\mathrm{f}$ to illustrate several general issue densities. TS of the $x$-ray laser $b$ function. The novelty of our stud inaccessible to TS experiments.

\section{THEORETICAL CONSIDE}

Consider a geometry of propagation, along $\boldsymbol{k}_{\theta}$ and the dire $\boldsymbol{k}$-vector in a plasma, $k=\mid \boldsymbol{k}_{0}-\boldsymbol{k}$ correlation function contributing define two regimes of the incoh electrostatic plasma mode resonar defines form of the electron densi 